\title{
Teachers' Perspectives on a Curriculum Change: A Trinidad and Tobago Case Study
}

\author{
Pradeep Mathura \\ Trinidad and Tobago
}

\begin{abstract}
Based on qualitative research, this intrinsic case study approach was used to investigate teachers' perspectives on the implementation of the CAPE Entrepreneurship curriculum change in North Eastern Educational District. This study uses Rogan and Grayson (2003) framework of Curriculum Implementation which examines three constructs, Profile of Implementation, Capacity Factors and Support from Outside Agencies. Semi structured interviews were carried out with teachers or implementers of the curriculum from its inception in 2015 at three different schools in the Educational District. Although the teachers are enthusiastic about the curriculum change and sees it as an on-going process to improve curriculum in an effort to increase student learning, their implementation efforts are constrained by a multitude of challenges. The study provides insights into what works and what doesn't, therefore the findings raised questions with regard to professional development for teachers and greater support from the Caribbean Examination Council (CXC) and Ministry of Education (MOE) as it pertains to the implementation process. It also highlighted the lack of resources and its impact on student performance, as well as the need to move away from the top down approach to communication. The implications of this study point to the complex nature of curriculum implementation and the multifaceted roles that teachers must play for successful implementation to occur. Thus, the appropriateness of the curriculum change objectives and the realities of the Educational District classrooms calls for increased attention to the implementation process.
\end{abstract}

\section{Introduction}

Teachers are often required to implement curriculum changes and innovations that are developed by external agents. These agents may or may not be familiar with the teachers' perspectives and viewpoints or even the specific classroom context in which the innovation is to be implemented. If teachers' views are not sufficiently taken into account the already challenging nature of implementing something new can be exacerbated. There are many conceptualizations of curriculum implementation. Carl [48] defines curriculum implementation as the application phase of not only core syllabi but also the school's broad curriculum, every subject curriculum and every lesson unit. While Guro and Weber [48] define curriculum implementation as a continuous, negotiated, contested, unpredictable process with policy adaptations resulting in unexpected outcomes. It is noted that these definitions advocate that curriculum implementation is a complex process, which requires intensive planning by the designers and the implementers.

Fullan [19] states that the implementation phase "consists of the process of putting into practice an idea, program, or set of activities and structures new to the people attempting or expected to change." In many cases, these curricula are well-designed and the aims they are intended to achieve are laudable. However, all too often the attention and energies of policymakers and politicians are focused on the 'what' of desired educational change, neglecting the 'how' [4].

The CAPE Entrepreneurship curriculum was developed by Caribbean Examination Council (CXC) in 2013 for written exams in 2015. However, the official launch took place in Trinidad and Tobago on May 15th 2014, where CXC partnered with the Chamber of Commerce. CAPE Entrepreneurship was one of 5 new subjects introduced across the Caribbean at that time and they were named "a new generation of CAPE subjects." Trinidad and Tobago was used as the pilot country for this launch since it is well known for its entrepreneurial talent. The curriculum was new and exciting therefore teachers took the opportunity to implement it in their classrooms.

The Ministry of Education of Trinidad and Tobago in collaboration with CXC highlighted the need for Entrepreneurship to be taught to students at the secondary level, since it provide an avenue of training that would eventually help the Caribbean countries to escape the cycles of dependency. The students will learn how to start a business and maintain a profitable business [50].

\section{Statement of the Problem}

The CAPE Entrepreneurship syllabus seeks to fill the void in the continuum from idea generation to 
venture creation. The syllabus intends to inform students of ways to access these training, technical support, funding and legislative incentives. It addresses fundamentals of entrepreneurial behavior and thinking. Engaging students in practical experiences through idea generation and opportunity identification. Teaching them to implement, manage and harvest a venture. The syllabus will acquaint students with the essentials of business ownership, legal and regulatory frameworks, the importance of market research, feasibility analysis, and the development of a business model in order to successfully compete in the global marketplace.

Furthermore, the curriculum should contribute to the development of the 'Ideal Caribbean Person', as agreed by CARICOM Heads of Government. It will essentially support "the creative imagination in its various manifestations and nurtures its development in the economic and entrepreneurial spheres in other areas of life". In keeping with UNESCO pillars of learning, students will learn to know, to do and transform oneself and society in a sustainable way.

Though the content may seem plausible on paper the implementation of this curriculum may not be as smooth as expected. The implementation stage is often overlooked when studying educational changes. Therefore, this study will allow teachers to share their perspectives on the factors that may inhibit or facilitate the implementation of the new CAPE Entrepreneurship in the North Eastern Educational District (NEED). Also, it is important to note that it is at the implementation stage that many curriculum changes fail. This is supported by Fullan [16], as he posited that curriculum change is often destined to fail, because the correct implementation protocols is not properly enforced. Also, according to Asebiomo [47], no matter how well formulated a curriculum may be, its effective implementation is essential towards achieving the desired goals of education and this is because the problem of most curriculum changes arises at the implementation level. Therefore it is crucial for research to be done for this curriculum change and to investigate the success of its implementation.

\section{Theoretical Framework}

In the past few decades, almost all CARICOM countries have been involved in educational reforms, particularly in development of new curricula. Time and again, these curricula are well-designed and have impressive aims to achieve. Nevertheless, in many cases their implementation has resulted in less-than desirable outcomes and led to waste of considerable resources, time, and effort since well-intentioned policies were never translated into classroom reality [42].

This study uses the Rogan and Grayson [41] framework to explore the factors which influence the implementation process of the CAPE Entrepreneurship curriculum change in schools in the North Eastern educational District with some adaptations.

The framework draws on the school development, educational change, and science education literature, in an attempt to overcome some of the shortcomings of earlier frameworks developed by Beeby and Verspoor and Wu [41]. Beeby [40] categorized schools and educational systems according to four developmental stages (Dame School, Formalism, Transition and Meaning), and assumed that schools progress from 'lower' to 'higher' stages. However, Beeby's model undervalues the complexity of an educational system and focuses only on teachers, making no reference to other aspects of the school context.

The more comprehensive model, which was developed by Verspoor and $\mathrm{Wu}$ [41] and later on adapted by De Feiter et al. [41] broadens the focus of development by including factors related to teachers, curriculum and school. However, this model neglects students even though they play an important role in the implementation process [18]. Similar to Beeby model, it proposes four stages of development: Unskilled, Mechanical, Routine and Professional. This model also implies a linear view of curriculum change, moving from one stage to the next higher stage. Consequently Rogan and Grayson [41] posited that both models therefore tend to obscure the complex and idiosyncratic nature of the process. Rogan and Grayson [41] centers their theory of implementation on three main constructs: Profile of Implementation, Capacity to Support Innovation and Support from Outside Agencies.

The first construct, 'Profile of Implementation' assists in understanding, analyzing and expressing the extent to which the objectives of the curriculum changes are put into practice. It recognizes the fact that there can be many ways of putting a curriculum into action. However, it assumes that some broad commonalities of what constitutes excellence will emerge. The profile also takes into consideration that there can be different levels at which implementation might be said to occur. Therefore, implementation of a new curriculum is not an all-or-nothing proposition [41]

The second construct, 'Capacity to Support Innovation' attempts to explain that there are factors that can support or hinder the implementation curriculum changes in schools. This construct recognizes that schools differ in terms of their ability to implement innovations. Possible indicators fall into four categories: physical resources, school ethos and management, teacher factors, and student factors. Poor Physical resources and conditions can shortchange even the performance of the best of teachers and learners. The school ethos and management are not the same, yet they are considered together as they 
are closely intertwined, particularly in schools in developing countries.

Also the school ethos can have serious impacts on the implementation of curriculum changes. If the school is in disarray and not functioning well, innovation cannot or will not be implemented. Therefore the teacher and learner factors have the most direct bearing on our chosen unit of analysis (the classroom), physical resources such as what is in the classroom (or whether there is a classroom at all) and aspects of the school ecology such as whether classes take place, also influence what will take place at the classroom level [42].

Furthermore, Fullan [16] highlights the importance of both the teacher and students in the implementation process. Teachers play a pivotal role in reform processes, and factors such as their background, training, subject matter knowledge, motivation, commitment to teaching, and attitudes towards proposed innovation influence their capacity and willingness to implement change. Likewise, the background of students, and the kind of strengths and constraints they might bring to the school are crucial [4].

Additionally, a range of issues can influence student attitudes to learning and responses to change. These include their home environments, parental commitment to education, health and nutrition, and proficiency level in the language of instruction. The impact of these four factors along with capability of schools to support innovation is likely to be dynamic and changing over time.

Thirdly, the 'Support from Outside Agencies' construct describes the kinds of actions undertaken by outside organizations. Stakeholders such as the Ministries of Education, examining bodies, and businesses in the community can influence implementation either through support or sanction. In many developing countries, outside agencies may also involve international development agencies and local or international NGOs [4]. The sub-constructs are divided into two: material support and nonmaterial support. The material support may include provision of physical resources such as buildings, books, or apparatus, and direct support to students (such as school-lunch programmes) whereas the Non-material support is mostly provided in the form of professional development.

In terms of CARICOM countries professional development is perhaps one of the most visible and obvious ways in which outside agencies attempt to bring about change in schools. As the literature on 'learning organization' suggests teacher professional development can also be promoted through cooperation and support among teachers [4]. Therefore, it can also be regarded as a sub-construct of school capacity. Each construct and its relevant factors are seen in Figure 1.

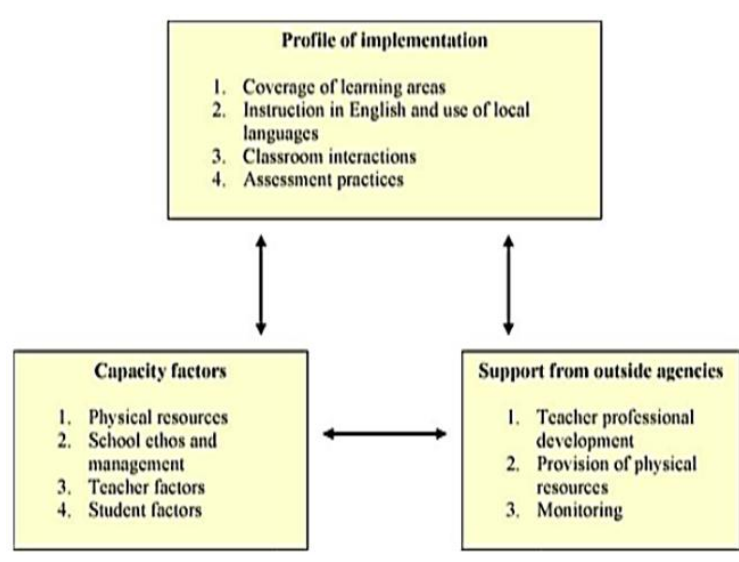

Figure 1. Analytical Implementation Framework [41]

\section{Research Design}

Based on the nature of the research issue, a qualitative methodology proved to be the most appropriate data collection method for this study. "Qualitative research is a situated activity that locates the observer in the world, qualitative researchers study things in their natural settings, attempting to make sense of, or interpret phenomena in terms of the meanings being to them" [35]. A case study approach was used as it enables the exploration of change management and the context in which it was occurring [52]. The framework for this research is built upon the philosophical assumptions of Ontology, Epistemology and Axiology. Ontology which deals with the commitment to a hermeneutic understanding of reality, the theory of interpretation and the shared meanings of social constructs [11]. These were evident in this study, as semi structured interviews and the varying responses of the teachers' perspectives were explored, as the researcher welcomed the multiple realities that exist. Additionally, epistemology focuses on how we know what we know [12] or the nature of the relationship between the knower or would be knower and what can be known [52], therefore the researcher built a relationship with the participants, in this case the teachers, in order to gain insight into their perspectives about implementation of the curriculum change

Three teachers from three different schools in the North Eastern Educational District were chosen for this study and they were interviewed for roughly 40 minutes each. They were chosen based on purposive sampling, which is a sampling strategy that is non probabilistic [35]. Purposive sampling is premised on the assumption that the investigator is seeking to discover, understand and gain insight and as a result, a sample from which the most can be learned must be selected [35]. The three participants were given pseudonym, Agent A, Agent B and Agent J. They 
were interviewed for roughly 40 minutes each in order to get that rich thick data and to allow them to feel comfortable and share their experiences and perspectives in a safe environment.

In addition, the participants were chosen because they were the first implementers of the CAPE Entrepreneurship curriculum change and the researcher will be able to gain the perspectives of the facilitators and barriers that the teachers faced when implementing this curriculum change.

According to Merriam [35], interviews are the best techniques to use when conducting intensive case studies of a few selected individuals. Given that the researcher wanted to 'understand and gain insights,' interviews were deemed most appropriate as it allowed for in-depth understanding and reflection of experiences [11]. Therefore rich thick descriptions were gathered from the participants in the study, as the researcher paid attention to intonation, pace of speech and questioning, as well as facial and bodily gesticulations to ensure that the participants were comfortable. In addition to the semi structured interviews, observation was used.

In order to prevent the researcher biases in the study, the researcher continually re-evaluated impressions of respondents and challenge pre-existing assumptions and hypotheses, Furthermore the researcher, by asking quality questions at the right time and remaining aware and focused on sources of bias, the researcher was able to get the truest respondent perspectives which ensured that the resulting research lived up to the highest qualitative standards. Furthermore, permission was sought form the Ministry of Education and the University of the West Indies to conduct this research, thereby adding to the ethical considerations of the research being adhered too.

The interviews were conducted and audiotaped with the teachers' permission, the researcher manually transcribed each recording. This transcriptions were printed out and with pencil in hand the researcher read and re -read each transcripts in their entirety several times, trying to immerse in the data and get a holistic view of the interview before breaking it into parts [11] This was done in order to develop a familiarity with the different information collected. Eventually, as patterns developed as the transcripts were read over and over, shorts notes of initial thoughts and ideas were written in the margins of these transcripts. This allowed the researcher to see commonalities and abnormalities, and thereby was able to code and create emergent themes. The coding of the data involved aggregating the text or visual data into small categories of information and then assigning a label to the code; descriptive codes were use [12].

Two (2) major limitations were faced by the researcher, firstly, time constraints, in that the time frame to conduct and analyze the data received were too short, therefore the meeting between the interviewer and interviewee prove to be difficult as assignments and work related issues got in the way. Secondly, having to rely solely on interviews because of time constraints posed a problem as it limited the data that could have been collected for the research.

\subsection{Research Questions}

The overarching research question which guides the study is:

What are teachers' perspectives of the factors that influence the implementation of the CAPE Entrepreneurship curriculum change?

The following sub-questions were derived:

1. What are teachers' perspectives of the factors that facilitate the implementation of the CAPE Entrepreneurship curriculum change?

2. What are teachers' perspectives of the challenges to the implementation of the CAPE Entrepreneurship curriculum change?

\section{Ethical Consideration}

Guba [39] developed four (4) constructs that correspond to the criteria employed by the positivist investigator they are, credibility (in preference to internal validity), transferability (in preference to external validity/generalizability), dependability (in preference to reliability) and confirmability (in preference to objectivity). These constructs are necessary when conducting qualitative research to ensure that the research is trustworthy [44]. Lincoln and Guba [39] argue that ensuring credibility is one of most important factors in establishing trustworthiness. Therefore the adoption of research methods were well established, the development of an early familiarity with the culture of participating teachers before the first data collection dialogues take place were conducted. This was achieved via consultation of appropriate documents and preliminary visits to the schools themselves and finally the research used triangulation [44]. Patton [39] posits that triangulation refers to the use of multiple methods or data sources in qualitative research to develop a comprehensive understanding of phenomena. Hence the semi structured interviews, observation and document analysis were used in tandem to ensure credibility of the study. In addition, it is important for the researcher to establish a relationship of trust with the participants so they can be comfortable and honest in their disclosures. All documents indicating that ethical considerations was are saved. Additionally, the researcher did "Member Checking" [39] with the participants, where they reviewed a summary of the data analysis procedure and a summary of the final 
results of the inquiry and finally there was researcher reflexivity, where the researcher self-disclose his assumptions, beliefs, and biases.

\section{Limitations and Delimitations of the study}

Shenton [44] highlighted the construct transferability, he posits that the findings of a qualitative project then to be specific to a small number of particular environments and individuals and it is impossible to demonstrate that the findings and conclusions are applicable to other situations and populations. In addition, dependability of qualitative research tends to vary because of the changing nature of the phenomenon scrutinized by qualitative researchers these factors acted as a delimitation to the study.

The researcher faced two (2) major limitations. Firstly, time constraints, in that the time frame to conduct and analyze the data received were too short, therefore the meeting between the interviewer and interviewee prove to be difficult as assignments and work related issues got in the way. Secondly, having to rely solely on interviews because of time constraints posed a problem as it limited the data that could have been collected for the research. Therefore should the time have been permitted a more comprehensive research could have been done.

\section{Findings of the Study}

\section{Research Question 1}

What are teachers' perspectives of the factors that facilitate the implementation of the CAPE Entrepreneurship curriculum change?

All three teachers expressed that they were enthusiastic about the CAPE Entrepreneurship Curriculum change. Teachers' views on curriculum implementation process are imperative in ensuring the success of a curriculum [48]. Also Fullan [17] agrees that the success of any educational review depends on what teachers do and think. Therefore, it is important to note that the need for a new curriculum was recognized by the implementers and this acted as a motivator to implement the curriculum change.

It was a really interesting subject to offer at CAPE level, because it was related to the business field and I thought it was important for the students to be offered something new especially since it would have focused on helping students become involved in setting up and establishing their own business and providing interesting or unique products which is what our economy, the national economy looking for people with entrepreneurial spirit.

(Agent A, interview 2018)

It is a necessary skill, because the economy is changing and with the change in the economy in T\&T we have an increasing need for students to open their own business. So that whereas before when the economy was a little bit better, you could have find students getting jobs easily. Now you will find that it is now much more difficult, so that when they learn this skill from the exposure to starting their own business they at least have an extra option if they want they can open there own business. So I think it is necessary and a very good course. I love teaching the entrepreneurship.

(Agent J, interview 2018)

With entrepreneurship you can apply the principles to any area, it is an important area and yeah, actually it is my favourite subject, favourite.

(Agent B, interview 2018)

Small class size was seen as a facilitator of the implementation process, since the teachers believe that they were able to interact with their students to a greater extent and have better class discussions. This was explained by Pedder [40] in that as class size increases, teachers tend to lose scope to choose from their repertoire of skills to increase the time available for academic activities. Also in bigger classes, more time is needed for non-academic activities in terms of management and control of discipline. Peddler [40] also posits that teachers mentioned that they were spread too thinly across students in larger classes and that better quality of support was available to students in small than in large classes. Also monitoring, checking and providing appropriate feedback is more difficult with larger classes as compared to that of smaller classes.

The class size affects the performance, I have observed because the class size in entrepreneurship in my school is very small and you find that the students are doing better, because in the class, because the size is small I am able to focus on each student and in a sense get each student to get engage. I engage all of them. If the class size was like 20 or more then it would have been very difficult to get every single person, I would not have the time to get every single person to contribute every class, but with the small class size I am able to get each child involved in the class, since we started the entrepreneurship the class size ranged from 10-15.

(Agent J, interview 2018)

Class size is not a problem, we have small classes 20 to 22 . And we could do group work. Which helps them in the future. The teamwork is good, I like it. 
(Agent B, interview 2018)

All three teachers alluded to the fact that the Curriculum change was interesting to students and provided good opportunities for them, like starting their own person, this motivated them to do well. This is supported by a broad based university level analysis found that "student engagement is linked positively to desirable learning outcomes such as critical thinking and grades" [9].

Despite the challenges, they overall love the subject because they were from a business background as well, accounts econ, POB, so they had love the subject no matter what. Also the students when enrolled for the class they saw it was interesting for them too. I have like two students from 2016 who went on to study it at tertiary level it is worthwhile.

(Agent A, interview 2018)

All three teachers indicated that they possessed the diploma in education and this training placed them in a better position to use a myriad of teaching strategies in the classroom. They believe they were able to meet the educational needs of their students in effecting the curriculum change. It should be noted that effective in-service teacher training is crucial for successful implementation of the curriculum [47]. Furthermore teacher training is important since, Fullan [16] explained that difficult classroom conditions, the absence of training, an inappropriate school environment, insufficient resources and mismatched high stakes assessment are inhibitors to curriculum reform at the classroom level. In addition, Beggs [6] found that one of the top three barriers to adoption of curriculum is the lack of training for teachers.

Entrepreneurship is like a living subject and for me the children should be able to become come part of it. Put in terms of a potential entrepreneur and see if they can move in that direction they will better understand what they supposed to do and how to complete task and so on. I used the flip classroom, well that was because of Dip Ed right. It was really good in that a lot of students was really intrigued in getting the material before. So they came to class having the advantage and they like that. We generally use discussions and cases and so on and pull little videos and so on from different areas.

(Agent B, interview 2018)

Well we had to use class discussion, I used a lot of the business videos to supplement, a lot of it I had to use websites related to the topic. The main strategies were class discussion use of videos, and we had done a field trip.

(Agent A, interview 2018)
From my stint at the DipEd programme I have learnt that if students effectively realize the importance of real life and what each subject that they do and how they are all interrelated then they will be more interested in the subject, hence they have to discuss with me. You will never walk into my entrepreneurship class and not see students talking if they not talking I am not teaching, that is how it operates we have to have discussion.

(Agent J, interview 2018)

Two teachers highlighted that administration was supported of the curriculum change and that they encouraged the teachers to follow through. They even provided resources and relevant materials as needed. This is supported by study after study which reinforces that effective principals build the collective capacity and capability for productive change to occur [43]. In addition the paricipants expressed that the networks built amongst their colleagues were crucial to the implementation process since they were able to discuss and troubleshoot concerns that they may have with the curriculum. This is reinforced by Whitaker [43] who highlights that a key factor in successfully leading change is the capacity to give deliberate attention to the building and development of an organizational culture conducive to collaboration, participation and change.

\section{Research Question 2}

What are teachers' perspectives of the challenges to the implementation of the CAPE Entrepreneurship curriculum change?

The teachers all highlighted that there was a time constraint when implementing the curriculum change. They indicated that the curriculum change required an SBA to be done which was essential to the curriculum, however it needed intense ground work to be done and this is time consuming. Also the teachers indicated that curriculum content required that the teacher be current and update, which placed additional burden on the teacher to do further research which took additional time. A study conducted in Saudi Arabia by Al-Alwani [6] found that lack of time is the main barrier affecting teachers' implementation of curriculum. In addition, Pace [8] posited that when instructional time has been so restricted, there is no time for higher order discussions, and this would affect curriculum implementation.

So it is a lot of background work from the individual teachers to get the work done. The main problem was scheduling a time to sit with the owner to conduct the interview. Definitely because it have the SBA component which is $60 \%$ but at the end of the day the SBA will take them only so far that was a lot 
of work too, a lot of work for the students and the teacher.

(Agent A, interview 2018)

Yeah they have the SBA, but a more hands on, I know it is difficult with the CAPE subject with the time frame. More resources, from the teachers' perspective, the curriculum easier in that it is less content than the MOB, but I guess you have to do more, more work as a teacher before, you have to stay current.

(Agent B, interview 2018)

Sometimes yes I find myself doing the teacher student classroom, but majority of the times I am like changing gears so like I sometimes I will be teaching the children and be like wait, this is a practical subject I should not be teaching this much and I may revert, but with the entrepreneurship class I try as much as possible because I want the students to really get the true value of the subject which is understanding how to be an entrepreneur, but it can be time consuming.

(Agent J, interview 2018)

The students factors highlighted were financial problems, absenteeism and low student abilities, and these acted as barriers to the implementation process because the three teachers had problems executing the curriculum successfully. However, Fullan [16] posited that children are vastly underutilized resources and that society is complex, hence children characteristics and needs are diverse. Therefore teachers must find a way to not only allowed them to be part of the solution, but in many cases, encourage them for they may even have better ideas and solutions.

The issue was learning the work. The challenge also come from other students who are not working on par like some students were too distracted with their own personal situations. Yeah probably they felt the entrepreneurship was easier and they did not follow through completely and it was getting to be tedious on the teacher to get them to finish the SBA, and in one case they did not turn up for their oral assessment

(Agent A, interview 2018)

My entrepreneurship class is not like that they are involved from the start to the finish, so at any one point in time though I will constantly test to make sure that they are on the same page with me. Also you will find that the students are not grasping the concepts too well, sometimes they will just go class relax, not really take on the classes.

(Agent J, interview 2018)
Once you direct them, you have to be able to direct them because by themselves, no way. Also You realize that many students know stuff but they don't know how to apply it and well you know, at least not here, in that, children not going to buy books anyhow you take it. Also some students hardly coming to school now.

(Agent B, interview 2018)

Lack of resources was considered a major challenge hindering the implementation of the curriculum change, this was explicitly stated by all three teachers. They highlighted that a relevant textbook for the curriculum change is not provided by the relevant authorities. Also classroom were not available for one of the teacher to do classes. In addition the use of projectors and multimedia was limited since it most times were being used by other colleagues. Also internet connection was non-existent in all three schools thereby limiting the use of videos or online resources. This is supported by Guthrie and Guthrie [51] who acknowledged the contextdependent nature of curriculum change and commented that curriculum reform progress had been limited and uneven due to their inappropriateness to the skills of teachers, the conditions under which teachers work, and the resources available. Furthermore Dello-Iacovo [51] pointed out that insufficient resources, conceptual ambiguity and conservative resistance in the exam-oriented education system will hamper the implementation of a curriculum change. In addition Cheng and Chueng [9] postulated that Curriculum implementation depends on availability of resources and that inadequate resources limit curriculum implementation.

No, sadly at the time, but I think they still working on stuff, but by the time they provided a textbook, I think it was not enough and there was a lot of gaps, in terms of the textbook not fulfilling what was required in the syllabus, it was not enough in the textbook, and I can say that for a fact. And the people who had done the textbook was aware of the situation and was working on editing but I haven't seen an edited version since. But I think they are working on it.

(Agent A, interview 2018)

In terms on the market yes, but very expensive. But most of the material... They basically have two textbooks, right, they mostly use one more than the other. But most of the material in terms of what in the market that they could actually purchase is more catered for university level. Projectors are available but it is limited, so use of a particular room for instance if I want to do any online I cannot use the form 6 class it is a dead zone, totally, total dead zone even with data, a total dead zone. In terms of 
internet use it is the library or the AV room. So that is a hindrance for me, because it had times, you want to get things going, so me now I have to organize things before and save it.

(Agent B, interview 2018)

The textbook when I started off this programme was difficult to get because they did not publish a textbook as yet as I actually had to use the internet to gather information, but now we have a text book that we are working with but still, limited information in terms of having a text that is suited for the syllabus, it might be a general entrepreneurship text which is more suited for tertiary level students so it will be difficult. In terms of projector use and stuff I don't get a room or a projector to do those classes so sometimes I will have to, actually there was a lot of times I had to have my classes outside of a room, on a pres-t-con bench with the group of students because of lack of room.

(Agent B, interview 2018)

The three teachers indicated the curriculum was not clear and there was ambiguity mainly with the Internal Assessment (IA) aspect of the curriculum. This caused a problem since the teachers were left confused as to how they should introduce the IA to the students, since there was little clarity specifically with the mark scheme for the IA. However, Fullan [18] stresses the importance of clarity during and throughout the period of implementation, stating that an absence of it can represent a major problem. He further maintains that quite often teachers and others find that the proposed changes are not very clear in practice [16]. Therefore, care must be taken so that the change process provides teachers with clear, specific details about what is required, and that changes are not implemented on a superficial basis [18]. Hence with clear expectations, teachers are more likely to own the process [48].

There is a scoring rubric for both Unit 1 and 2 where you have to do an SBA on. So it is details on both, they will give you a rubric but then they don't give you much more than a rubric, so it is like a puzzle you figure out what is required for under this section in the rubric. as to the details as to what supposed to be in each section and you know it was very different at that time

(Agent B, interview 2018)

Some of the things were not specific, in terms of what they want you to do and how deep they want you to go. There is always that concern. All CAPE syllabus same problem. In the syllabus, initially you have to read certain things, it have a part where marks are allocated here, but then when you check the rubric, but then what they asking for but you say where this marks come out from. So you have to stick to the full rubric. In unit 2 for market research specifically, there is a part where they talk about customer analysis, but then you don't see all those thing brought out in the actual mark scheme. So you what they should actually do. So that is one of the challenges, and basically for any new curriculum area trying to fully understand what they really want to find out, especially with $\mathrm{CXC}$ you realized that they are very vague.

(Agent B, interview 2018)

I followed that syllabus but then questions came to me about the structure of the SBA, some persons were asking about the word limit and when I read the instructions on the syllabus it was very vague so it wasn't clear on what was the word limit for unit 2 and what was the word limit for unit 1 and what should go where. Actually there was a marking scheme, there is two marking scheme for the business plan and market research. One was not adding up to 60 and the other was adding up to 60 . So I was confuse when you giving me 2 piece of information that is against each other.

(Agent B, interview 2018)

In terms of balkanization and department support only one teacher highlighted that there was no support from the business department. The teacher also expressed that another teacher within the department who implements the curriculum change as well is not proficient in the area and refuses to take advice from anyone. This acts as a barrier to the implementation process and is reinforced by Hargreaves and Huberman and Miles [21] who envisage that collegiality can promote professional growth and generate internally school improvement; therefore, it can also be viewed as a means of ensuring effective implementation of the externally imposed change.

School culture was seen as a barrier since the three teachers' stated that it had some impact on their practice. Agent A indicated that the curriculum was being supported because it provided a great selection of subjects for students to choose, hence increasing their chances of scholarship, this agent $\mathrm{A}$ identified as a culture of the school, the drive for academic excellence. Whereas agent $\mathbf{J}$ indicated that the culture of his school was toxic in that students depended mainly on the teacher. Therefore the culture of a school can be a positive influence on learning or it can seriously inhibit the functioning of the school [23]. More so, it is highlighted that the teacher is envisaged as the key element in creating school ethos or cultures conducive to change and can take in account the fact that a proposed change may not be realized overnight [23].

Although Agent A and Agent B stated that administration was supportive in the implementation process, they still joined in with Agent $\mathbf{J}$ in 
highlighting the lack of administrative support which acted as a barrier to the implementation of the curriculum change. Mathibe [49] points out that principals should create a climate and culture of success in schools by making sure that there is room for self-expression, creativity, communication and motivation in all structures of the school. The information age dictates that principals need to understand the curriculum in order for them to become effective managers. Moreover, Fullan [16] posited that in the changing process, leaders are the key role in managing the change.

It was clear that all three teachers were not comfortable with the support from the exam syndicate (CXC). They all expressed dissatisfaction as they believe CXC continues to not provide the required resources for the effective implementation of the curriculum. Smith [34] posited that the lack of appropriate resources diminishes the potential of sound implementation in the classrooms. In addition CXC introduces a curriculum change using a top down approach whereby they create the curriculum and send it off to be implemented in schools with little guidance and very limited avenues for feedback. Okoth [36] posited that when the implementing agent does not understand the curriculum requirements, they are likely to modify it to fit their understandings, which can lead to the unsuccessful implementation of the curriculum change.

No cxc sent no other resources. Also it is a subject and the new subject was not introduce in stages it was just introduced BAM!, just do it CAPE say go ahead and we did it, so it wasn't like a phase situation where they interact with teachers around the Caribbean, like hi we are have this subject and we are proposing to introduce we will like your input. I am not so sure what went on there.

(Agent B, interview 2018)

as a new subject area, how much time they really give it, they should try to get feedback on an ongoing basis. Getting on the teachers who actually implementing the curriculum to see any issues. I know money is an issue but they could use technology to get feedback from teachers. So you can see where you can make changes and suggestions.

(Agent B, interview 2018)

when CXC amends a syllabus there is nowhere for a teacher to know, when there is an amendment, so when I got the entrepreneurship syllabus initially, when it was launched. I followed that syllabus but then questions came to me about the structure of the SBA when CXC revises a syllabus how do they communicate this to a teacher, I did not know, and how do I find out, do I have to always be checking the website, that is kind of difficult to do all the time.

(Agent B, interview 2018)

In addition the three teachers explained that lack of government support was evident where the curriculum change was implemented in the schools and one two day workshop was held to facilitate professional development for the teachers. However this proved futile since some teacher were not informed of the workshop while others only attended only one day since it was not as beneficial and effective as expected. In addition the teachers expressed the concern the curriculum officers do not visit their schools to provide feedback or to ensure that the curriculum is being implemented in the way it should. Kihato and Kabemba [34] argue that a wellcoordinated support system at national, provincial, district and school level could help teachers to face the difficulties in the classroom. They posit that more subject specialists should be trained, given that subject advisors are ideally suited for providing teachers with the necessary support in their classrooms and for assisting them in alleviating difficulties that teachers encounter in specific learning areas. Hence teacher's knowledge is therefore important to enable correct conceptualization of a curriculum change [36].

\section{Recommendations}

Firstly, the examination syndicate CXC, in partnership with the Ministry of Education should host a number of physical forums to highlight the Curriculum itself as well as amendments that would have been made after it initial launch. This forum can be used to discuss issues as well as recommendations that teachers may have. In this way teacher will be feel a part of the curriculum process and not separate from it. Also, this foster in teachers a sense of ownership of the curriculum and they will be further motivated to implement the curriculum.

Secondly, CXC and MOE should foster better communication channels in disseminating information. In the world of technology today, there are a number of ways that teachers can keep connected with MOE and $\mathrm{CXC}$ for instance that a variety of conferencing software like webinar, go to meeting, zoom and blackboard collaborate to name a few. These channels can be used to give updates as well as feedback to questions that teachers may have concerning the curriculum.

Another recommendation deals with resources, MOE and CXC in partnership should make available a textbook that is relevant, up to date and pertinent to the curriculum at hand. It should be aligned to the syllabus in that way it will reduce the time and effort required by teacher to search through the content find the information that is appropriate for the curriculum. 
This is important as textbooks are the number one resource and source of information for students.

The MOE need to provide ample funding to the various school administrations so that they can purchase the required resources for the teachers as they take in this curriculum. This will help in building teacher morale as they will feel better prepared to teach their classes as well provide update and relevant content to their students.

Also MOE partnering with CXC can host professional development workshops whereby teachers can be trained in different teaching and assessment strategies. Also the workshops can also be used to train teaching on answering case studies for the written papers and also on the administering of the internal assessment. This will allow teachers to feel comfortable about the curriculum and buy in to the process.

CXC and MOE allow has to re-evaluate their approach to curriculum change, it should not be top down as is customary, but more so it should be bottom up, where the teachers are allowed to be a part of the process and they will be able to give feedback as to the implementation of the curriculum. Also in this way teachers will not implement the curriculum in an ad hoc manner but will be better prepared and knowledgeable to implement it. More if they are part of the process then it will lead to a seamless flow amongst all the stakeholders involved, CXC, MOE, Teacher, students, parents, and business community. Leadership at the schools need to place a greater emphasis on the curriculum itself. It should not be seen as just another subject to choose, hence the seriousness of the subject and how it ties in with the real world should be acknowledge. Also, the principal plays an important role in the implementation process therefore they need to be more active in the process and not take a hands-off approach.

Principals should pay attention to class size and student absenteeism as these factors if escalated can have severe impacts of the implementation of the curriculum. Also the principals are a key ingredient in school culture and ethos. Therefore, greater emphasis should be placed on building a culture to accept and support change should be fostered so that teacher and students can benefit.

Finally, CXC and MOE can do proper monitoring of the curriculum change, visits to the school should be entertained, since they can see the actual curriculum practice, and they will be able to share and advise teachers appropriately. Also, in this way they can have a hands-on approach and will be able to have that one on one direct interaction with the teachers of the various schools.

\section{Acknowledgments}

I will like to thank my wife and kids for their love and support, the University of the West Indies, my supervisor Ms. Sharmila Harry for her continuous words of encouragement and all the participants involved in the study.

\section{References}

[1] Akar, E. Ö. (2014). Constraints of Curriculum Implementation as Perceived by Turkish Biology Teacher. Ted Eğitim Ve Bilim, 39(174). doi:10.15390/eb.2014.3092

[2] Alan C.K. Cheung, Ping Man Wong, (2012). Factors affecting the implementation of curriculum reform in Hong Kong: Key findings from a large-scale survey study. International Journal of Educational Management, 26(1), 39 - 54.

[3] Ali Ostovar-Namaghi, S. (2017). Language Teachers' Evaluation of Curriculum Change: A Qualitative Study. The Qualitative Report,22(2), 391409. Retrieved November 30, 2017.

[4] Altinyelken, H. K. (2010). Curriculum change in Uganda: Teacher perspectives on the new thematic curriculum. International Journal of Educational Development,30(2),151-161. doi:10.1016/j. ijedudev.2009.03.004

[5] Barrow, D., \& Delisle, J. (2010). Evaluation of some teachers' concerns, and levels of use of the lower secondary SEMP. Caribbean Educational Research Journal, 2(1), 3-16.

[6] Basak, S. K., \& Govender, D. W. (2015). Development of a Conceptual Framework Regarding the Factors Inhibiting Teachers Successful Adoption and Implementation of ICT in Teaching and Learning. International Business \& Economics Research Journal(IBER),14(3),431.doi:10.19030/iber.v14i3.92 08

[7] Berlach, R. G. (2011). The Cyclical Integration Model as a Way of Managing Major Educational Change. Education Research International, 1-8. doi: $10.1155 / 2011 / 963237$

[8] Caribbean Examiner: CXC at 40 (PDF Download Available).(n.d.).Retrievedfromhttps://www.bing.co $\mathrm{m} / \mathrm{cr}$ ? IG=4A55694C167B4F039C3C59DF9AF1036 $\mathrm{D} \& \mathrm{CID}=12834 \mathrm{DA} 33 \mathrm{~F} 396 \mathrm{DF} 62322465 \mathrm{~F} 3 \mathrm{EC} 46 \mathrm{CCE}$ $\& \mathrm{rd}=1 \& \mathrm{~h}=\mathrm{EZmmTNFLSMA20gTzAhxNjJPesGUO}$ sLV13ad0rrFCYM\&v=1\&r=https://www.researchga te.net/publication/282326013_Caribbean_Examiner_ CXC_at_40\&p=DevEx.LB.1,5494.1

[9] Chen, Y. N., Chen, H. M., Huang, W., \& Ching, R.] K. (2006). E-Government Strategies in 
Developed and Developing Countries. Journal of Global Information Management,14(1), 23-46. doi:10.4018/jgim.2006010102.

[10] Chowthi-Williams, A., Curzio, J., \& Lerman, S. (2016). Evaluation of how a curriculum change in nurse education was managed through the application of a business change management model: A qualitative case study. Nurse Education Today,36, 133-138. doi:10.1016/j.nedt.2015.08.023

[11] Creswell, J. W. (2008) Educational research: Planning, conducting, and evaluating quantitative and qualitative research. Columbus, N.J.: Pearson Prentice Hall.

[12] Creswell, J. W. (2007). Qualitative Inquiry and Research Design: Choosing among the five traditions. London, UK: Sage Publications. Creswell, J. (1998). Qualitative inquiry and research design. Thousand Oaks, CA.: Sage.

[13] Darling-Hammond, L. (1990). Instructional Policy into Practice: "The Power of the Bottom over the Top". Educational Evaluation and Policy Analysis, 12(3), 339. doi:10.2307/1164357.

[14] Donaldson, G. (2014). Teacher Education and Curriculum Change in Scotland. European Journal of Education,49(2), 178-191. doi:10.1111/ejed.12077.

[15] Esmi, K., Marzoughi, R., \& Torkzadeh, J. (2015). Teaching learning methods of an entrepreneurship curriculum. Journal of Advances in Medical Education \& Professionalism,3(4), 172-177. Retrieved December 5, 2017.

[16] Fullan, M. (2001). The NEW meaning of educational change. New York, NY: Teachers College Press.

[17] Fullan, M. (1985). Change Processes and Strategies at the Local Level. The Elementary School Journal,85(3), 391-421. doi:10.1086/461411.

[18] Fullan, M. (1983). Evaluating Program Implementation: What Can Be Learned from Follow Through. Curriculum Inquiry,13(2), 215-227. doi:10.1080/03626784.1983.11075881.

[19] Fu, Y., \& Sibert, S. (2017). Teachers' Perspectives: Factors That Impact Implementation of Integrated Curriculum in K-3 Classrooms. International Journal of Instruction,10(01), 169-186. doi:10.12973/iji.2017.10111a.

[20] Griffith, S. A. (2017). Lessons from CXC for Caribbean higher education institutions. Quality
Assurance in Education,25(2), 224-236. doi:10.1108/qae-10-2015-0040.

[21] Hargreaves, A. (1997). Cultures of teaching and educational change. In M. Fullan (Ed.), The challenge of school change. Illinois: Skylight Training and Publishing.

[22] Hargreaves, A. (1997). Introduction. In A. Hargreaves (Ed.), Rethinking educational change with heart and mind: 1997 ASCD yearbook. Virginia: Association for Supervision and Curriculum Development.

[23] Hall, G. E., \& Hord, S. M. (2006). Implementing change: patterns, principles, and potholes. Boston: Pearson.

[24] Harris, A., Jones, M., Cheah, K. S., Devadason, E., \& Adams, D. (2017). Exploring principals' instructional leadership practices in Malaysia: Insights and implications. Journal of Educational Administration,55(2), 207-221. doi:10.1108/jea-052016-0051

[25] Harry, S. N., \& Mitchell, B. (2015). An Investigation into Teachers' Perspectives of the Factors that Facilitate the Implementation of the eCAL Curriculum Change Initiative in Trinidad and Tobago. International Journal for Digital Society, 6(3),1058-1065. doi:10.20533/ijds.2040.2570.2015. 0130 .

[26] Hickling-Hudson*, A. (2004). Towards Caribbean 'knowledge societies': Dismantling neocolonial barriers in the age of globalisation. Compare: A Journal of Comparative and International Education,34(3),293-300. doi:10.1080/0305792042 000257130 .

[27] Hinde, E. R. (2002). Switching classes: Teachers' conceptualizations of change in their professional lives. Unpublished doctoral dissertation. Arizona State University.

[28] Is Your School's Culture Toxic or Positive? (n.d.). Retrieved from http://www.educationworld. com/a_admin/admin/admin275.shtml

[29] Jones, M., \& Harris, A. (2014). Principals leading successful organizational change. Journal of Organizational Change Management,27(3), 473-485. doi:10.1108/jocm-07-2013-0116.

[30] Launch of CAPE Entrepreneurship. (2014, May 21). Express.

[31] Louisy, D. P. (2004). Whose context for what quality? Informing education strategies for the 
Caribbean. Compare: A Journal of Comparative and International Education,34(3), 285-292. doi:10.1080/0305792042000257121.

[32] Jennings, Z. (1994). Innovations in Caribbean School Systems: Why some have become institutionalized and others have not. Curriculum Studies, 2(3), 309-331. doi:10.1080/09659759400 20303.

[33] Jones, E., \& Schoburgh, E. (2004). Deconstructing Policy-Making and Implementation Issues in a Caribbean Context. Social and Economic Studies,53(4), 35-61.

[34] Mellegård, I., \& Pettersen, K. D. (2016). Teachers' response to curriculum change: Balancing external and internal change forces. Teacher Development, 20(2), 181-196. doi:10.1080/13664 530.2016 .1143871 .

[35] Merriam, S. B. (2009). Qualitative Research: A Guide to Design and Implementation, USA: JosseyBass.

[36] Okoth, T. A. (2016). Challenges of Implementing a Top-down Curriculum Innovation in English Language Teaching: Perspectives of Form III English Language Teachers in Kenya. Journal of Education and Practice,7(3), 169-177.

[37] Orafi, S. M. S. (2013). Effective Factors in the Implementation Of ELT Curriculum Innovations Scientific Research Journal, (1)5, 14-21.

[38] Ornstein, A. C., \& Hunkins, F. P. (2008). Curriculum: Foundations, principles, and issues (5th ed.). Boston, MA: Allyn and Bacon.

[39] Patton, MQ. (2002). Qualitative Evaluation and Research Methods (2nd ed.) Newbury Park, CA: Sage Publications.

[40] Pedder, D. (2006). Are small classes better? Understanding relationships between class size, classroom processes and pupils learning. Oxford Review of Education,32(2), 213-234. doi:10.1080/03054980600645396.

[41] Rogan, J. M., \& Grayson, D. J. (2003). Towards a theory of curriculum implementation with particular reference to science education in developing countries. International Journal of Science Education,25(10), 1171-1204. doi:10.1080/.

\section{9}

[42] Rogan, J. M. (2007). An uncertain harvest: A case study of implementation of innovation. Journal of Curriculum Studies,39(1), 97-121. doi:10.1080/00220270500532448

[43] Shen, Y. (2008). The Effect of Changes and Innovation on Educational Improvement. International Education Studies, 1(3). doi:10.5539/ies.v1n3p73

[44] Shenton, A. K. (2004). Strategies for ensuring trustworthiness in qualitative research projects. Education for Information,22(2), 63-75. doi:10.3233/efi-2004-22201

[45] Smeed, J., Bourke, T., Nickerson, J., \& Corsbie, T. (2015). Testing Times for the Implementation of Curriculum Change. SAGE Open,5(2), 215824401558101 . doi:10.1177/2158244015581018.

[46] Stoll, L., \& Fink, D., (1996). Changing our school culture. Philadelphia :Open University Press.

[47] Syomwene, A. (2013). Factors Affecting Teachers' Implementation of Curriculum Reforms and Educational Policies in Schools: The Kenyan Experience." Journal of Education and Practice, (4) $22,80-86$.

[48] Taole, M. J. (2015). Towards a meaningful curriculum implementation in South African schools: Senior phase teachers' experiences. Africa Education Review,12(2), 266-279. doi:10.1080/18146627.2015. 1108005 .

[49] Taole, M. (2013). Teachers' Conceptions of the Curriculum Review Process. International Journal of Educational Sciences,5(1), 39-46. doi:10.1080/09751 122.2013.11890059.

[50] Welcome to CXC® Store. (n.d.). Retrieved from https://cxc-store.com/.

[51] Yan, C. (2012). 'We can only change in a small way': A study of secondary English teachers' implementation of curriculum reform in China. Journal of Educational Change,13(4), 431-447. doi:10.1007/s10833-012-9186-1.

[52] Yin, R. K. (2004). Case study research: Design and methods. Thousand Oaks: Sage. 